\title{
The pathogenesis and medical treatment of hepatic encephalopathy
}

\author{
A. E. READ \\ University of Bristol
}

IT IS ALWAYS difficult to treat clinical disorders which have no certain cause and thus from the outset there is real difficulty in the handling of the problem I have been asked to talk about. I intend, therefore, to discuss some of the experimental work related to this disorder and to indicate where possible points at which these studies may indicate lines of treatment. I shall deal with this by considering the various body organs which show evidence of deranged metabolism though the individual part that any organ plays is difficult to assess and probably variable in different clinical situations.

Hepatic coma has been considered to be due to intoxication of the brain by ammonia and it must be admitted that there is much evidence to show that ammonia is directly toxic both to the patient with liver disease as well as in certain circumstances to normal subjects. This almost certainly represents a considerable oversimplification of the problem and other possible theories concerning the aetiology of this disorder include:

(1) The possibility that ammonia acts by depleting the brain of NADH or $\alpha$-ketoglutarate.

(2) That it diverts ATP to the formation of glutamine.

(3) That it is incorporated into some other toxic nitrogen containing substance, e.g. $\gamma$ aminobutyrate.

It is now necessary to consider the ways in which various body organs are concerned in ammonia metabolism in order to understand some of the treatments that have been suggested. I do not incidentally intend to discuss the place of surgical operations on the colon in treatment or renal dialysis. One fact of some considerable clinical importance is that hepatic coma in a patient with established chronic liver disease is often the result of some metabolic insult such as infection, an alimentary bleed or the use of diuretic or sedative drug. Reversal of these situations may result in a return of the patient to their previous though not necessarily normal neuro-psychiatric status.
The brain

This 'target' organ is of obvious importance in the pathogenesis of hepatic encephalopathy and any condition which upsets brain 'integrity' is obviously a possible cause of the disorder. Awareness and arousal are a normal function of the activity of deeply placed centres in and around the reticular formation. Sedative drugs would be expected to have a more profound effect in patients with hepatic encephalopathy simply because of an augmenting effect on reticular depression. Exclusion or inactivation of these drugs would be an important part of the therapeutic programme of patients with hepatic encephalopathy who had received them. It is uncertain whether any beneficial effect could be obtained by using drugs which activate the् reticular formation and presumably such drugs would be no more effective in this type of encephalopathy than in any other.

Various neurohormones, and in particular the neuroamines dopamine, adrenaline, noradrenaline and 5-hydroxytryptamine (5HT, serotonin) may have a part to play in the pathogenesis of this disease, in that there may be a blood-brain barrier for some of these substances so that local production is dependent on a supply of precursors-and because 5-hydroxytrytophan (5HTP) production could be defective in the cirrhotic liver. Borges and colleagues (Borges, Merlis \& Bessman, 1959) have used intravenous infusions of 5HTP to treat heptic encephalopathy postulating a cerebral deficiency of serotonin and claim to produce improvement. Monoamine oxidase inhibitors which prevent the breakdown of various amines have also been suggested as a possible therapy for this disorder. Certainly neuroamines may be important; though Dawson \& Sherlock (1958) noted a deterioration rather than an improvement in one of their patients treated with the monoamine oxidase inhibitor 'Marsilid'. Blood ammonia levels may fall despite this deterioration perhaps due to the inhibition of amine breakdown to ammonia. Methyldopa and reserpine are drugs which can deplete neuroamine stores so that one might expect the patient 
with liver disease to show neurosensitivity to them. An important in vitro relationship exists between brain metabolism as measured by $\mathrm{O}_{2}$ uptake and the presence of indolic substances in the incubating medium. The identification of the neuro-depressant substances Factor 1 and $\gamma$ aminobutyrate (GABA) has raised the question of its possible implication in hepatic encephalopathy though blood levels are not elevated (Goetchens \& Webster, 1965).

\section{The kidney}

There are various alterations of renal function which could play a part in the pathogenesis of hepatic coma. The first, renal failure-which is not an uncommon complication of cirrhosiscould by increasing the total urea load increase the production of ammonia. Certainly ureases, both bacterial and non-bacterial in the alimentary tract convert urea to ammonia and in renal failure the gastric production of ammonia is known to be increased (Lieber \& Lefevre, 1958) accounting for neutralization of gastric acidity. The fact that diuretic drugs can precipitate renal failure in cirrhosis has an important bearing on this problem.

Chronic liver cell disease is often accompanied by hypokalaemia. This condition is often difficult to correct with supplements, particularly in the presence of diuretic drugs where potassium loss is particularly likely to accompany a poor sodium diuresis. The fact that hepatic encephalopathy is precipitated by this and possibly other electrolyte deficiencies is well appreciated (Read et al., 1959). Owen and his colleagues (Owen, Johnson \& Tyor, 1961) have studied the effects of infusing ammonia on the renal handling of this substance. Renal ammonia production which occurs from the deamination of glutamine is decreased under these circumstances despite an increase in urinary ammonia excretion. The extra ammonia is then of non-renal origin. The kidney thus serves to lower blood ammonia levels in hyperammonaemia by reducing its release into the renal veins, and by increasing urinary excretion. The therapeutic lessons to be learned are related to the early detection of hypokalaemia and renal failure in the cirrhotic.

\section{The muscles}

Exercising muscle forms large amounts of ammonia, high blood levels being recognized over 30 years ago in patients with status epilepticus (Luck, Thacker \& Marrack, 1925). Presumably muscular activity due to fits could be the cause of an increased ammonia load in patients with hepatic encephalopathy though this feature is rarely seen. Sustained exertion has been shown by Schwartz and colleagues (Schwartz, Lawrence \& Roberts, 1958) to produce a small but consistent rise in peripheral ammonia levels in patients with liver disease-this effect being irrespective of that due to change in $\mathrm{pH}$.

The major action of muscle in hepatic encephalopathy is otherwise a beneficial one, muscle acting as an important ammonia acceptor. In this function it performs more efficiently than the brain and does not suffer from any barrier between blood-stream and organ which could deplete it of ammonia acceptors such as glutamic acid. In advanced cases of encephalopathy decreasing $\mathrm{A}-\mathrm{V}$ differences of ammonia in the blood and in some cases actual release of ammonia from muscles represent the failure of this protective muscle function.

Ammonia may be diverted from muscle and, therefore, escape into the arterial circulation through dilated skin and muscle vessels. This circulatory adjustment is found in patients with liver-cell failure and presumably it could be aggravated by fever and anaemia. The diuretic acetazolamide may also inhibit muscle uptake of ammonia (Dawson et al., 1957) - certainly it can precipitate hepatic encephalopathy in patients with liver disease in whom it is used. Unfortunately the parameters of muscle function which may play a part in the pathogenesis of hepatic encephalopathy are not amenable to therapy.

\section{The lungs}

Hyperventilation, arterial hypoxia, a rise in the arterial $\mathrm{pH}$ and a low $\mathrm{PCO}_{2}$ are not infrequent complications of hepatic encephalopathy (Vanamee et al., 1956). The low $\mathrm{PCO}_{2}$ was the basis for treating this condition with $\mathrm{CO}_{2}$ inhalations though deterioration rather than improvement resulted from this treatment (Posner \& Plum, 1960) despite a fall in blood ammonia levels. The reason for this sensitivity of brain to $\mathrm{CO}_{2}$ in patients with hepatic encephalopathy is unknown though this is probably quite non-specific. Various degrees of arterial oxygen desaturation are found in some patients with liver disease and this is usually correlated with the presence of $\mathrm{A}-\mathrm{V}$ communications in the lungs. Basal lung collapse in patients with hepatic cirrhosis with ascites may result in hypoxia due to the presence of collapsed non-ventilated pulmonary tissue. Ammonia toxicity is potentiated by anoxia. Certainly Warren \& Schenker (1960) showed that anoxia potentiated the $\mathrm{LD}_{50}$ of ammonia compounds in mice and that this effect was irrespective of $\mathrm{pH}$ or ammonia uptake. 
The increased work-load of the respiratory muscles in dyspnoeic patients with liver disease may also be a factor resulting in the increased production of ammonia (Berry et al., 1960). Certainly elevated blood ammonia values are found in dyspnoeic patients without liver disease (Dutton et al., 1959).

\section{The stomach}

Gastric urease can produce ammonia from the breakdown of urea. This enzyme is of nonbacterial origin and is formed by the gastric parietal cell (Fitzgerald \& Murphy, 1948) though it is possible that urease of bacterial origin may occur in the achlorhydric and bacterially contaminated stomach of the patient with liver disease. Renal failure by increasing the urea load can therefore lead to the increased gastric production of ammonia. Gastric secretion results in increased levels of ammonia in gastric juice (Fleshler \& Gabuzda, 1965). Further, gastric secretion in response to histamine results in a rise of blood ammonia levels (Turner \& Arpad, 1963). Thus stimulation of the stomach by food or by the direct action of secretagogues may act as a stimulus to urease and, therefore, gastric ammonia production.

Several means of suppressing urease activity have been employed therapeutically. Gastric cooling and gastric suction may have an effect on enzyme levels and Thomson \& Visek (1963) have produced urease immunity by injecting patients with hepatic encephalopathy with injections of a potent but foreign urease contained in the soya bean. Beneficial results are claimed though toxic effects are not rare and multiple injections are required. Aceto-hydroxamine (Aoyagi \& Summerskill, 1966) will inhibit urease in vitro and prevents the production of ammonia from the substrate hydroxy-urea. It has had some limited success in patients with hepatic encephalopathy (Fishbein, Carbone \& Hochstein, 1965) and it is possible that it could be employed to supplement the action of antibiotics.

\section{The small bowel}

This is the site of nitrogen and protein absorption. Total exclusion of protein is an essential part of the medical treatment of this disease though as yet the differential toxicity of different types of protein is not well defined though Fenton, Knight \& Humpherson (1966) suggest that milk and cheese protein may be less toxic. The differential toxicity of individual amino acids is even less well appreciated. L-methionine is known to be a precipitant of hepatic coma (Phear et al., 1956) and protection against this effect is obtained with antibiotics. Studying the effects of ڤ equimolecular doses of L-tryptophan, L-alanine 3 and L-methionine, we have not noted any startling $\stackrel{\mathbb{Q}}{\varrho}$ differences in the response to them as judged $C$ by the EEG though of the three L-tryptophan $\overrightarrow{\vec{A}}$ seems the most powerful. This effect of tryptophan is a rapid one and not related to small bowel absorption and metabolism.

Neomycin is well known to produce a beneficial effect in hepatic encephalopathy. It is usually thought that this effect is solely related to its anti-bacterial properties though neomycin can $\vec{\circ}$ block the uptake of L-tryptophan and sugars into the intestinal cell and in clinical practice is $\vec{\omega}$ known to cause a mild malabsorption syndrome. $\frac{\mathrm{O}}{0}$ Perhaps some of the action of neomycin in protecting against hepatic coma lies in its ability to produce protein malabsorption. Intestinal motility may also be a factor of importance as intestinal or atony and dilatation perhaps related to hypokalaemia may occur. Non-absorbable carbohydrates of such as sorbitol ensure the rapid delivery of the $\circ$ small bowel contents to the colon. The small bowel may be the site of an increased bacterial population (Martini et al., 1957) and antibiotics may then have a beneficial effect both on small $\frac{c}{\omega}$ and large bowel flora.

\section{The colon}

Most of the ammonia produced in the gut of large bowel origin. Ammonia levels are thirteen times higher in colonic venous blood than in venous blood draining other parts of the bowel. The bacterial population of the colon may be altered by various means but most specific- $\overrightarrow{\vec{A}}$ ally by antibiotics. Neomycin remains the most $\frac{9}{3}$ suitable antibiotic for general purposes and it suppresses $E$. coli and some but not all of the ammonia-forming bacteria which are mainly Bacteroides, Proteus and Klebsiella. Ammonia is 3 . produced by means of bacterial ureases. There may be something to be said for the constant examination of stool specimens of patients with $ᄋ$ hepatic encephalopathy who are being treated $₹$ with antibiotics. In this way the faecal culture can 웅 be 'tailored' to an appropriate antibiotic in which $D$ case newer antibiotics such as cephaloridin may be useful. Faeces may not, however, be a good measure of actual bacterial content of the gut. $\sigma$

Colonic bacteria can be suppressed by the im- $N$ plantation of non-ammonia producing bacterial $\mathrm{\omega}_{\mathrm{W}}$ such as $L$. casei. Macbeth and his colleagues (Macbeth, Kass \& McDermott, 1965) fed patients 0 with hepatic encephalopathy on a skimmed milk medium in which $L$. casei had been cultured. $\stackrel{?}{?}$ There was a fall in arterial ammonia, clinical 0 improvement and a fall in faecal urease activ- $O$ 
ity. Similar effects may be obtained with a freeze dried preparation of Lactobacilli (Enpac) though the method is slow and inferior in our experience to that of neomycin (Read, McCarthy \& Heaton, 1966). A highly resistant strain of $L$. casei resistant to neomycin might possibly have an additive effect to that of neomycin alone. Lactobacilli suppress growth of other organisms because of their ability to produce an acid and unsuitable medium. The non-absorbable carbohydrate lactulose may encourage the growth of lactobacilli by its breakdown in the colon to form lactic and acetic acids. Its beneficial effect has been reported in hepatic encephalopathy (Bircher et al., 1966).

Aperients and enemas can have a striking and beneficial effect in some patients with hepatic encephalopathy (Summerskill, Wolfe \& Davidson, 1957).

\section{The liver}

The two major metabolic disadvantages most likely to be associated with hepatic encephalopathy which result from liver-cell disease are firstly an opening up of vascular shunts both within and outside the organ which therefore allows portal blood to flow directly into the systemic circulation and secondly a defective hepatic conversion of ammonia to urea. The vulnerable step seems likely to concern that from citrulline to arginine (Pearl \& McDermott, 1958). As a result of observations such as these it has been thought useful to employ L-arginine in the treatment of this disorder though results are disappointing despite an effect on ammonia handling (Harper \& Owsley, 1958).

The cirrhotic liver is extremely sensitive to a fall in arterial blood pressure and this must be guarded against by fluid replacement and the careful use of pressor agents. It is likely that the close relationship of the liver to lipoprotein metabolism, together with the known toxicity of protein renders glucose given by the intravenous route 'sparing' on liver metabolism.

\section{The cell}

The distribution of ammonia between extracellular fluid and the cell being $\mathrm{pH}$ dependent, predictable changes in ammonia partition can be made on acid and alkaline perfusion. Extracellular metabolic alkalosis is detrimental to the patient because it encourages ammonia to enter cells. Warren \& Nathan (1958) have demonstrated the increased toxicity in mice of alkaline as opposed to acid ammonium salts. Patients have been treated by acid infusions (Warren et al., 1960) and though blood and CSF ammonia levels respond appropriately no clinical improvement results.

Tissue temperature is also important-hyperthermia having an enchancing effect experimentally on ammonia toxicity whilst hypothermia may be protective. It is difficult, however, to disassociate these effects from those due to changes in $\mathrm{pH}$, etc.

\section{Other concepts}

Acute hepatic coma can be treated in addition to the above ways by exchange transfusion (Kiley et al., 1958 ; Trey, Burns \& Saunders, 1966) or by hepatic perfusion (Eiseman, Van Wyk \& Griffin, 1966) using in the latter case the isolated pig's liver or human cadaver liver. In neither circumstances is the cause of the effect in improving the patient's clinical status known. Presumably in the former method there is dilution of some toxic product or products by the transfused blood whilst in the latter hepatic function is temporarily restored towards normal by the donor liver.

These methods are a useful supplement to existing ones but their chance of producing a return of the patient to consciousness is low and the patient in the case of chronic liver disease still remains susceptible to further attacks of coma and the hazards of deteriorating liver function.

\section{References}

Aoyagi, T. \& Summerskill, W.H.J. (1966) Inhibition by acetohydroxamic acid of human mucosal and faecal urease specific activity. Lancet, i, 296.

Berry, J.N., OWen, E.E., Flanagan, J.F. \& Tyor, M.P. (1960) The effect of acute hyperventilation on the blood ammonia concentration of patients with liver disease. J. Lab. clin. Med. 55, 849.

Bircher, J., Muller, J., Guggenheim, P. \& Haemmerli, U.P. (1966) Treatment of chronic portal-systemic encephalopathy with lactulose. Lancet, i, 890.

Borges, F.J., Merlis, J.I. \& Bessman, S.P. (1959) Serotonin metabolism in liver disease. J. clin. Invest. 38, 715 .

Dawson, A.M. \& Sherlock, S. (1958) The effect of the amine-oxidase inhibitor Marsilid on ammonium metabolism in liver disease. Clin. Sci. 17, 587.

Dawson, A.M., De Groote, J., Rosenthal, W.A. \& SherLOCK, S. (1957) The effects of Diamox on ammonia metabolism in liver disease. Clin. Sci. 16, 413.

Dutton, R., Nicholas, W., Usar, C., Fisher, J. \& ReNZETTA, A.D. (1959) Blood ammonia in chronic pulmonary emphysema. New Engl. J. Med. 261, 1369.

EISEMAN, B., VAN WYK, J. \& GRIfFIN, W.O. (1966) Methods for extracorporeal hepatic assist. Surg. Gynec. Obstet. 123, 522.

Fenton, J.C.B., Knight, E.J. \& Humpherson, P.L. (1966) Milk-and-cheese diet in portal-systemic encephalopathy. Lancet, i, 164.

Fishbein, W.N., Carbone, P.P. \& Hochstein, H.D. (1965) Acetohydroxomate: bacterial urease inhibitor with therapeutic potential in hyper-ammonaemic states. Nature (Lond.) 208, 46. 
Fitzgerald, O. \& MURPhy, P. (1948) Role of gastric urease (letter). Nature (Lond.) 162, 896.

FleshleR, B. \& GABUzDA, G.J. (1965) Effect of ammonium chloride and urea infusions on ammonium levels and acidity of gastric juice. Gut, 6, 349 .

Goetchens, J.S. \& Webster, L.T. (1965) $\gamma$-aminobutyrate and hepatic coma. J. Lab. clin. Med. 65, 257.

HARPER, H.A. \& OWSLEY, J.Q. (1958) Effect of arginine and glutamate on tolerance to intravenously administered ammonium chloride. Arch. Surg. 76, 766.

Kiley, J.E., Pender, J.C., Welch, H.F. \& Welch, C.S. (1958) Treatment of hepatic coma by exchange blood transfusion. New. Engl. J. Med. 274, 473.

Lieber, S. \& Lefevre, A. (1958) Ammonium and intermediate metabolism in hepatic coma. Acta clin. Belg. 13, 328.

LUCK, J.M., ThACKer, G. \& MarraCK, J. (1925) Ammonia in the blood of epileptics. Brit. J. exp. Path. 6, 276.

Macbeth, W.A.A.G., Kass, E.H. \& McDermotT, W.V. (1965) Treatment of encephalopathy by alteration of intestinal flora with lactobacillus acidophilus. Lancet, i, 399.

Martini, G.A., Phear, E.A., Ruebner, B. \& Sherlock, S. (1957) The bacterial content of the small intestine in normal and cirrhotic subjects: relation to methionine toxicity. Clin. Sci. 16, 35.

OWEN, E.E., Johnson, J.H. \& TYOR, M.P. (1961) The effect of induced hyperammonemia on renal ammonia metabolism. J. clin. Invest. 40, 215.

Pearl, D.C. \& McDermott, W.V. (1958) A vulnerable and rate-limiting step in urea synthesis in patients with hyperammoniaemia. Proc. Soc. exp. Biol. (N.Y.), 97, 440.

Phear, E.A., Ruebner, B., Sherlock, S. \& Summerskill W.H.J. (1956) Methionine toxicity in liver disease and its prevention by chlortetracycline. Clin. Sci. 15, 93.

Posner, J.B. \& Plum, F. (1960) The toxic effects of carbon dioxide and acetazolamide in hepatic encephalopathy. J. clin. Invest. 39. 1246.
Read, A.E., Laidlaw, J., Haslam, R.M. \& Sherlock, S. (1959) Neuropsychiatric complications following chlorothiazide therapy in patients with hepatic cirrhosis: possible relation to hypokalaemia. Clin. Sci. 15, 93.

Read, A.E., McCarthy, C.F. \& Heaton, K.W. (1966) Lactobacillus acidophilus Enpac in treatment of hepatic encephalopathy. Brit. med. J. i, 1267.

Schwartz, A.E., LaWrence, W. \& Roberts, K.E. (1958) Elevation of peripheral blood ammonia following muscular exercise. Proc. Soc. exp. Biol. (N. Y.), 98, 548.

SUMmerskill, W.H.J., Wolfe, S.J. \& DAVIDSON, C.S. (1957) The metabolism of ammonia and L-keto-acids in liver disease and hepatic coma. J. clin. Invest. 36, 361.

Thomson, A. \& Visek, W.J. (1963) Reduction of portal venous pressure in cirrhotic patients with bleeding from oesophageal varices by administration of a vasopressin derivative, phenylalanine ${ }^{2}$-lysine ${ }^{8}$-vasopressin. Amer. $J$. Med. 36, 825.

TreY, C., Burns, D.G., \& Saunders, S.J. (1966) Treatment of hepatic coma by exchange blood transfusion. New Engl. J. Med. 274, 473.

Turner, M.D. \& ARPAD, O.A. (1963) Effects of histamine on arterial blood ammonia in man (letter). Nature (Lond.), $198,590$.

Vanamee, P., Poppel, J.W., Glicksman, A., Randall, H.T. \& RoBERTS, K.T. (1956) Respiratory alkalosis in hepatic coma. Arch. intern. Med. 93, 762.

WARRen, K.S., Iber, F.L., Dolle, W. \& Sherlock, S. (1960) Effect of alterations in blood $\mathrm{pH}$ on distribution of ammonia from blood to cerebrospinal fluid in patients with hepatic coma. J. Lab. clin. Med. 56, 687.

WARREN, K.S. \& NATHAN, D.G. (1958) The passage of ammonia across the blood-brain-barrier and its relation to blood pH. J. clin. Invest. 37, 1724.

WARREN, K.S. \& SCHENKER, S. (1960) Hypoxia and ant monia toxicity. Amer. J. Physiol. 199, 1105. 